\title{
AN EVALUATION OF THE MAXWELL-BOLTZMANN ENTROPY MODEL OF THE APPALACHIAN STEAM COAL MARKET
}

\author{
Chin W. Yang*
}

\begin{abstract}
Since the early 1950's, there has been much effort expended in modeling interregional commodity flows. Among them are linear programming transportation models (e.g., Henderson); the Enke-Samuelson-TakayamaJudge models; the Leontief-Strout gravity models; and other econometric models. However, the entropy model has so far eluded description especially when implemented empirically. In this paper, we implement the MaxwellBoltzmann entropy maximization model to the Appalachian steam coal market. We then compare the solution of optimum coal shipments with that of the corresponding linear programming transportation and spatial equilibrium models. It is found that (1) the performance of the Maxwell-Boltzmann entropy model is comparable to that of the spatial equilibrium model and (2) the entropy has outperformed the linear programming transportation model in its simplest form in terms of predicting actual coal shipments.
\end{abstract}

\section{Introduction}

The modern era is witnessing tremendous advances in knowledge, especially in physics. The scope of classical mechanics has been greatly expanded by the introduction of both quantum mechanics and relativity. Economic science, however, viewed as a sister of mechanics by Walras or the mechanics of utility and self-interest by Jevons still relies heavily on the assumptions of utility maximization or cost minimization principles. In order to overcome such limited definition, we propose and implement the Maxwell-Boltzmann entropy model in which it is hypothesized that energy flows (e.g., shipment of steam coal) resemble the movement of particles in a closed physical system. Given $\mathrm{m}$ supply sources and $\mathbf{n}$ demand sinks, there is a tendency to shuffle and scramble ordered

*Associate Professor of Economics, Clarion University of Pennsylvania, Clarion, PA 16214. Author wishes to thank Professor T. Takayama for his valuable comments, especially on the constraint equations when used in the entropy model. However, any errors are the author's. In addition, he wishes to thank Professor R. Maggio and two anonymous referees for their critiques of the stochastic nature of the energy flows and the relationship between the potential entropy and the acid rain policy. things into disorder (Georgescu-Roegen, 1971). This is quite in contrast to the standard linear programming transportation problem, the objective of which is to minimize total transportation cost (or total energy). In such linear programming (LP) and quadratic programming (QP) (spatial equilibrium) models, the energy flows exhibit some regularity much like particle movements in ice. In contrast, energy flows are basically more volatile and stochastic in the form of steam in the entropy model and they do not obey long-recognized theorems in either the linear programming or spatial equilibrium models. As a matter of fact, it was proved by Evans (1973) that the linear programming model is a special case of the entropy model. Since such a model, to the best of our knowledge, has never been empirically implemented in the commodity market, we employ the data of the Appalachian steam coal market (Yang, 1979) to solve for the "optimum" solution under the assumptions of (i) maximizing Maxwell-Boltzmann entropy, (ii) minimizing Hitchcock-Koopmans' transportation cost, i.e., traditional LP model, and (iii) maximizing "net social payoff" (NSP or sum of consumer's and producer's surpluses) of the spatial equilibrium model. It is to be noted that the maximization of the NSP and the entropy is quite different: the solution to the former is based on estimated demand (utility) and supply (technology) rela tions in a spatial economy while the solution to the latter is dependent upon the assumption that there is an inherent tendency for commodity shipments to move toward a state of maximum spatial diffusion. Hence, a solution corresponding to the maximum NSP contains a flow pattern which may not possess the maximum spatial diffusion. On the other hand, a solution corresponding to the maximum entropy, given the identical preference and technology relations, implies a flow pattern which may not lead to a maximum economic welfare. We then discuss the comparative performance of the Maxwell-Boltzmann model and its policy implications, especially when transportation costs of commodities (or friction) are greatly reduced due to potential technological advances.

\section{Literature Review of the Transportation Models}

The transportation problem originated in physics. Hitchcock (1941), Kantorovich (1942) and Koopmans (1949) are generally credited for formulating the original 
transportation problem in which a friction function is to be minimized. Since the advent of the efficient solution algorithms developed by Dantzig (1951), and Chames and Cooper (1953), application of the model has proliferated due to more efficient computational procedures. In a market-oriented economy, Samuelson's influential work on spatial price equilibrium (1952) represents an extension of Enke's work on an electric analog (1951) in which prices are represented by voltages and physical commodity flows by amperages. The similarity between Koopmans' transportation model and the Maxwell-Kirchhoff law was indicated by Samuelson (1952) who cited Tucker (1950). In their classical paper, Takayama and Judge (1964) reformulated the Enke-Samuelson problem into a quadratic programming model in which linear market demand and supply functions are explicitly considered. Ever since, there have been a flux of applications: Hall, etc. (1975), Brooks (1975), Labys and Yang (1980, 1981), Nagy, etc. (1980), and Harker (1983), to name a few. In addition, Kennedy's world oil market (1974) and Khatri-ChhetriHite-Nyankori's water allocation problem (1988) are modeled in the form of a complementarity problem. In the case of multi-commodities with asymmetric demand and supply parameter estimators the linear complementarity programming (LCP) models may be preferred. However, such models were empirically implemented only in a few cases (Hashimoto 1977, Yang and Labys 1985).

Theoretical advances along the line of the EnkeSamuelson-Takayama-Judge model include: Thore's extension of the Takayama-Judge model (1982a, 1982b); new algorithm by Nagurney $(1986,1987)$; sensitivity analysis by Yang and Labys (1982), and Tobin (1987); transshipment problem by Tobin and Friesz (1983) and Chao (1983); iterative procedures by Irwin and Yang $(1982,1983)$; linear complementarity problem by Takayama and Uri (1983) and its solution condition by Smith (1984); flow dependent supply and demand by Smith and Friesz (1985); variational inequalities by Pang and Chan (1982); Daffermos (1983) and Daffermos and Nagurney (1984); Harker (1984); Tobin (1986); and Nagurney (1987). Despite tremendous theoretical advancements, these improved models are generally designed to search for the most efficient routes of commodity flows, based upon either maximizing welfare or satisfying some sets of equilibrium conditions. However, most of them share the same problem. For instance, there are very limited numbers of positive commodity flows to appear in the optimum solutions; and the optimal flows must obey so-called reciprocity condition (Yang, 1989). Furthermore, many successful applications of the LP and QP models were made on agricultural or energy commodities whose transportation costs constitute a significant portion of the market price. In light of the potential technological advancements in reducing transportation costs, it may be appropriate to search for an alternative model, i.e., a model which is not sensitive and geared to changes in transportation costs.

\section{Model Formulations}

Since all of these models originated from, and are extensions of the classical linear programming transportation problem, we first present its linear version:

$$
\begin{gathered}
\text { Minimize } Z=\sum_{i \in I} \sum_{j \in J} t_{i j} x_{i j} \\
\text { Subject to } \sum_{j \in J} X_{i j}=K_{i} \\
\sum_{i \in I} X_{i j}=D_{j} \\
X_{i j} \geq 0
\end{gathered}
$$

Where $I$ and $J$ are the integer sets or $I=\{i=1,2,3$, $\ldots, m\}$ and $J=\{j=1,2,3, \ldots, n\} ; X i j$ is the nonnegative commodity flow from supply region $i$ to demand region $j$; $t_{\mathrm{ij}}$ is the transportation related cost between region $\mathrm{i}$ and region $j ; K_{i}$ is the production capacity in supply region $i ; D_{j}$ is the consumption requirement in demand region $\mathrm{j}$. It is well-known in the literature that there cannot be more than $(m+n-1)$ positive commodity flows in the LP model (Gass, 1985). A standard quadratic programming model, as reformulated by Takayama-Judge, is more general than its linear programming version by introducing linear demand and supply equations, i.e., $P_{j}=a_{j}-b_{j} Y_{j}$ and $P_{i}=c_{i}+$ $d_{i} X_{i}$. Where $Y_{j}$ and $X_{i}$ are quantity demanded in the $j^{\text {th }}$ region and quantity supplied in the $i^{\text {th }}$ region, $P_{j}$ and $P_{i}$ are corresponding prices; $a_{j}$ and $c_{i}$ are the corresponding intercepts of estimated demand and supply equation; $b_{j}$ and $d_{i}$ are corresponding slope coefficients. The objective function is established to maximize the net social payoff (see Takayama-Judge, 1971) or

$$
\begin{array}{r}
N S P=\sum_{j} a_{j} Y_{i}-\frac{1}{2} \sum b Y_{j}^{2}-\underset{i}{\sum c_{i} X_{i}} \\
-\frac{1}{2} \sum d_{i} X^{2}-\underset{i}{i} \underset{i j}{\sum t_{i j}} X_{i j}
\end{array}
$$

subject to (2), (3), and (4) with $\mathrm{K}_{\mathrm{i}}$ and $\mathrm{D}_{\mathrm{j}}$ replaced by $\mathrm{X}_{\mathrm{i}}$ and $Y_{j^{*}}$ Again, the quadratic version of the transportation model shares the same problem of having no more than $\mathrm{m}+\mathrm{n}-1$ positive commodity flows (see Silbergerg, 1970 
and Yang, 1980). As a more general alternative, one can postulate that the behavior of inter-regional commodity flows resembles movements of particles in an isolated gaseous system (Wilson, 1974; Batten, 1983).

Such a concept of entropy was well grounded in the bedrock of physical facts. In a closed physical system, elements have a tendency to move toward an arrangement which can be organized in as many ways as possible, i.e., maximization of the entropy of a system (Nikjamp and Paelinck, 1974). For example, if we limit the solutions to be integer-valued, the maximum possible ways to assign 8 distinct objects to 3 locations is $8 ! / 3 ! 3 ! 2$ ! which is much greater than $8 ! / 8 ! 0 ! 0$ ! or $8 ! / 5 ! 3 ! 0$ ! or $8 ! / 4 ! 3 ! 1$. Such distribution is the most likely occurrence and in general corresponds to more spatial diffusions similar to thermal diffusions in thermodynamics.

In this paper we maximize the Maxwell-Boltzman entropy (Batten, 1983) in which coal flows (particles) are considered to be distinct subject to (2), (3), (4) with a constraint on the total transportation cost analogous to the total energy constraint imposed on systems of particles, or

$$
\begin{aligned}
& \text { Maximize } \log W \\
& \text { Subject to } \sum_{\mathrm{i} \in \mathrm{I}} \sum_{\mathrm{j} \in \mathrm{J}} \mathrm{t}_{\mathrm{ij}} \mathrm{X}_{\mathrm{ij}}=\mathrm{C} \\
& \text { And (2), (3), and (4) } \\
& \text { Where } \mathrm{W}=\prod_{\mathrm{i} \in \mathrm{I}}\left[\frac{\mathrm{K}_{\mathrm{i}} !}{\Pi \mathrm{X}_{\mathrm{ij}} !} \prod_{\mathrm{j} \in \mathrm{J}} \mathrm{X}_{\mathrm{j}}{ }_{\mathrm{j} \in \mathrm{J}}\right)
\end{aligned}
$$

where $h_{j}$ is the number of consumption depots in demand region $j$.

Since any monotonical transformation of $W$ gives the same result (Wilson, 1970, p. 5), and for mathematical convenience, we take the natural logarithmic function of $\mathrm{W}$ to rewrite (8) ${ }^{1}$ as:

$$
\begin{aligned}
\operatorname{Maximize} \log W= & \sum_{i \in I} \log \mathrm{K}_{\mathrm{i}} !-\sum_{\mathrm{i} \in \mathrm{I}} \sum_{j \in J} \log \mathrm{X}_{\mathrm{ij}} ! \\
& +\sum_{\mathrm{j} \in \mathrm{J}} \mathrm{D}_{\mathrm{j}} \log \mathrm{h}_{\mathrm{j}}
\end{aligned}
$$

Which is equivalent to

$$
\text { Maximize }-\sum_{i \in I} \sum_{j \in J} \log X_{i j} \text { ! }
$$

due to the fact that the constant terms of $\log \mathrm{K}_{i} !$ and $\mathrm{D}_{\mathrm{j}} \log$

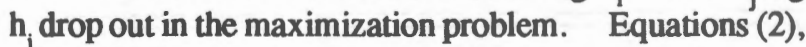
(3), (4), (7) and (9) constitute the Maxwell-Boltzmann entropy (MBE) model. The optimum solution $\left(X_{\mathrm{ij}}\right.$ 's) represents the most probable commodity flow distribution subject to the indicated constraints.

To illustrate some properties of the MBE models, we form the Lagrangian equation:

$$
\begin{aligned}
L & =-\sum_{i \in I} \sum_{j \in J} \log X_{i j} !+\sum_{i \in I} \gamma_{i}\left(K_{i}-\sum_{j \in J} X_{i j}\right) \\
& +\sum_{j \in J} \lambda_{j}\left(D_{j}-\sum_{i \in I} X_{i j}\right)+\beta\left(C-\sum_{i \in I} \sum_{j \in J} t_{1 j} X_{i j}\right)
\end{aligned}
$$

where $\gamma_{i}, \lambda_{j \beta}$, and are Lagrangian multipliers for (2), (3) and (7) respectively.

Differentiating (10) with respect to $\mathrm{X}_{\mathrm{ij}}$ and applying Stirling's approximation ${ }^{2}$, we have

$$
\frac{\partial L}{\partial X_{i j}}=-\log \bar{X}_{i j}-\bar{\gamma}_{i}-\bar{\lambda}_{j}-\bar{\beta}_{1 j}=0 \text { for all } \bar{X}_{i j}>0
$$

which may be reduced to

$$
\bar{X}_{i j}=e^{-\bar{\gamma}_{i}-\bar{\lambda}_{j}-\bar{\beta} t_{i j}}
$$

From (2) and (3), we have

$$
\begin{aligned}
& e^{-\gamma_{i}}=K_{i} / \sum_{j \in J} e^{-\bar{\lambda}-\beta t_{i j}}=K_{i} A_{i} \\
& e^{-\bar{\lambda}}=D_{j} / \sum_{i \in I} e^{-\gamma_{i}-\beta t_{i j}}=D_{j} B_{j}
\end{aligned}
$$

By substituting (12) and (13) into (11), we have

$$
\bar{X}_{i j}=K_{i} D_{j} A_{i} B_{j} e^{-\bar{\beta} t_{i j}}
$$

where $A_{i}$ and $B_{j}$ are the reciprocal of denominators of equations (12) and (13) respectively.

It is evident from (14) that the most probable distribution of the optimum commodity flows in the MaxwellBoltzmann formulation takes the form of the classical Newtonian gravity model with $\mathrm{e}^{-\beta \mathrm{k}}$ serving as a spatial deterrent factor. The fact that maximization of the entropy model leads to the derivation of the gravity formulation may also be found in Tomlin and Tomlin (1968). Perhaps, the most important application of the gravity model is one developed by Leontief and Strout (1963). ${ }^{3}$ They suggest that the inter-regional commodity flows take the form of:

$$
X_{i j}=\frac{X_{i} \cdot Y_{\cdot j}}{X \cdot .} Q_{i j}
$$

where $X_{i j}=$ shipment of the commodity from supply region $i$ to demand region $j$

$\mathrm{X}_{\mathrm{i}} \cdot \mathbf{=}$ total output in supply region $\mathrm{i}$ 
$Y_{\mathrm{i}}=$ total quantity demanded in demand region $\mathrm{j}$

$X . .=\sum_{i \in I} X_{i} \cdot=\sum_{j \in J} Y_{j}=$ aggregate amount of commodity produced and consumed in all the regions of an economy

$Q_{i j}=$ is an empirical constant which can be estimated from base year data.

Structural equation (15) formulated by Leontief and Strout is a variant of the gravity model derived from the Maxwell-Boltzmannentropy model. It should bepointed out that Leontief and Strout integrated the gravity formulation with conventional input-output analysis to model the inter-regional and inter-industrial linkage problem.

On the other hand, Evans (1973), Wilson (1970) and Wilson and Senior (1974) have demonstrated that the conventional LPT model is the limit of the entropy model as the lagrange multiplier $\beta$ of (7) approaches infinity and the value of (1) approaches (7), i.e., $Z=C$. This limiting property indicates that the LPT formulation is essentially a special case of the entropy model ${ }^{4}$. In the next section we will model the Appalachian steam coal market in terms of the Maxwell-Boltzmann entropy formulation. To the best of our knowledge, such an empirical application has not been made in the spatial commodity market.

\section{Implementation of the Model}

Supply and demand regions are specified in Table 1. The corresponding unit transportation costs are reported in Table 2, and the actually observed demand requirement $D_{j}$ 's and production capacity $K_{1}$ 's for 1973 are shown below (in $10^{15} \mathrm{BTU}$ 's):

$$
\begin{aligned}
& K^{\prime}=(1.2,0.93,0.75,0.05,0.24,1.73,0.32) \\
& D^{\prime}=(0.03,1.29,0.66,0.03,1.72,0.52,0.97)
\end{aligned}
$$

Coupled with observed data sets of transportation costs and $K_{i}^{\prime}$ 's and $D_{j}$ 's, the maximization of (8), while subject to (2), (3), (4), and (7), constitutes the framework of the Maxwell-Boltzmann Entropy model. Note that total energy level or transportation cost $C$ is set at the total actually observed transportation cost of steam coal in the Appalachian market, i.e., $\mathrm{C}=70.426$. The solution of the entropy model is reported in Table 3. To evaluate the comparative performance of the Maxwell-Boltzmann model, we employ the comparable data set to obtain the optimum solution of the standard linear programming and Takayama-Judge quadratic programming transportation models. ${ }^{5}$ These results are also reported in Table 3.

Table 1

\begin{tabular}{ll}
\hline Supply Region & Base Point \\
\hline 1. Pennsylvania, Maryland & Pittsburgh \\
2. Ohio & Cadiz \\
3. Northern West Virginia & Morgantown \\
4. Southern West Virginia & Beckley \\
5. Virginia & Bristol \\
6. East Kentucky, Tennessee & Pikeville \\
7. Alabama & Birmingham \\
Demand Region & Base Point \\
\hline 1. Connecticut, Maine, Massachusetts, & \\
2. New Hampshire, Rhode Island, Vermont & Beston \\
Washington, D.C., Maryland, Delaware & New York \\
3. Indiana, Michigan & Detroit \\
4. Illinois, Wisconsin, Minnesota & Chicago \\
5. West Virginia, Ohio, Kentucky & Cincinnati \\
6. Tennessee, Alabama, Mississippi & Birmingham \\
7. Virginia, North Carolina, South Carolina, & Columbia \\
\hline
\end{tabular}


Table 2

Unit Transportation Cost

(cents per $10^{6} \mathrm{BTU}$ )

\begin{tabular}{|c|c|c|c|c|c|c|c|}
\hline TO ${ }^{\text {FROM }}$ & 1 & 2 & 3 & 4 & 5 & 6 & 7 \\
\hline 1 & 19.1 & 22.2 & 20.2 & 20.5 & 21.2 & 24.3 & 26.8 \\
\hline 2 & 14.5 & 18.3 & 13.5 & 16.9 & 17.6 & 20.4 & 23.3 \\
\hline 3 & 13.2 & 13.8 & 11.8 & 16.6 & 20.3 & 16.7 & 19.8 \\
\hline 4 & 18.8 & 19.8 & 19.6 & 22.5 & 21.8 & 17.1 & 18.1 \\
\hline 5 & 15.1 & 13.3 & 13.7 & 12.6 & 17.2 & 13.4 & 15.7 \\
\hline 6 & 21.1 & 22.5 & 21.8 & 19.2 & 14.1 & 16.9 & 7.0 \\
\hline 7 & 21.0 & 24.0 & 20.9 & 16.5 & 14.7 & 13.6 & 14.3 \\
\hline
\end{tabular}

Source: See Mutchler, etc. and Yang (1980).

\section{Comparative Evaluations of the Maxwell-Boltzmann Entropy Model}

An examination of Table 3 reveals that there are 17 positive steam coal flows in the Maxwell-Boltzmann model versus 12 flows in the standard linear programming transportation model $^{6}$ and 13 flows in the Takayama-Judge model. Of 22 actually observed positive steam coal flows in the Appalachian market, 11 are correctly predicted by the entropy model while 8 and 10 coal flows are correctly predicted by the linear and quadratic programming transportation model, respectively. In terms of number of coal flows correctly predicted, the entropy model has a relative edge on the corresponding linear and quadratic programming model. To further facilitate the comparison, we define the following index:

$$
I=\sum_{i \in I} \sum_{j \in J} \frac{\left|\hat{x}_{i j}-x_{i j}\right|}{x_{i j}}
$$

where $\hat{\mathrm{H}}_{\mathrm{ij}}$ is the predicted energy flow from supply region $i$ to demand region $\mathrm{j}$; and $\mathrm{X}_{\mathrm{ij}}$ is the corresponding observed energy flow. The smaller the value $I$ is, the better the model may be. The value of I for the seven major steam coal flows $\left(X_{12}, X_{25}, X_{32}, X_{33}, X_{65}, X_{66}\right.$ and $\left.X_{76}\right)$ of the Maxwell-Boltzmann model is approximately $42.13 \%$, whereas the value of I for the corresponding linear programming model is $91.15 \%$.
This implies that the entropy model predicts $57.87 \%$ and the linear programming model predicts less than $10 \%$ of actual volumes of the Appalachian steam coal flows based on formula (16). Clearly, the LP model performs poorly in approximating the unpredictable coal flows especially in a market-oriented environment. However, the LPT model presented is an allocative tool in its simplest form. With other constraints included (e.g., coal quality, sulfur content, environmental regulations) the LPT model solution will better replicate market shipments. On the other hand, the solution of the quadratic programming spatial equilibrium model (Labys and Yang, 1980) using the identical transportation cost data is comparable to the result from the entropy model. The former predicted $62.52 \%$ of actual volumes of the Appalachian steam coal flows (see Table 3) versus $57.87 \%$ of the entropy model. To sum, it may be noted that the Maxwell-Boltzmann entropy model does outperform the corresponding linear programming model in terms of predicting both the number of steam coal flows as well as their actual volumes; and it also outperforms the quadratic programming model in terms of number of coal flows. However, potential applications of the entropy model in terms of current policies cannot be accomplished as conveniently as compared with the LP or QP model, since the concept of economic welfares, demand and supply are lacking in the model (Wilson and Senior, 1974). The simulation result shown in Table 4 is obtained from a potential one-cent per million BTU pollution tax imposed 
Table 3

Optimum Solution (in $10^{15}$ BTU) of the Appalachian Steam Coal Market

\begin{tabular}{|c|c|c|c|c|c|c|c|c|}
\hline To ${ }^{\text {From }}$ & $\begin{array}{l}\text { PA } \\
\text { MD }\end{array}$ & $\mathrm{OH}$ & $\begin{array}{l}\text { Northern } \\
\text { WV }\end{array}$ & $\begin{array}{l}\text { Southern } \\
\text { WV }\end{array}$ & VA & $\begin{array}{c}\text { East KY } \\
\text { TN }\end{array}$ & AL & $\begin{array}{l}\text { Total } \\
\text { Demand }\end{array}$ \\
\hline New England & $(0.03)$ & & 0.03 & & $\begin{array}{l}{[0.03]} \\
((0.042))\end{array}$ & & & 0.03 \\
\hline Mid-Atlantic & $\begin{array}{l}((1.025)) \\
1.03 \\
(0.697) \\
{[1.2]}\end{array}$ & $(0.162)$ & $\begin{array}{c}((0.195)) \\
0.21 \\
(0.432) \\
{[0.09]}\end{array}$ & 0.02 & 0.03 & & & 1.29 \\
\hline IN-MI & $\begin{array}{c}0.07 \\
(0.258)\end{array}$ & $\begin{array}{c}((0.304)) \\
0.240 \\
(0.226)\end{array}$ & $\begin{array}{c}((0.336)) \\
0.12 \\
(0.176) \\
{[0.66]}\end{array}$ & 0.03 & & 0.2 & & 0.66 \\
\hline North Central & 0.01 & $(0.03)$ & 0.01 & & & $\begin{array}{c}0.01 \\
{[0.03]} \\
((0.053))\end{array}$ & & 0.03 \\
\hline Ohio Valley & $\begin{array}{l}0.09 \\
(0.215)\end{array}$ & $\begin{array}{c}((0.708)) \\
0.690 \\
(0.512) \\
{[0.93]}\end{array}$ & $\begin{array}{c}0.38 \\
(0.142)\end{array}$ & $\begin{array}{l}((0.035)) \\
\\
(0.05) \\
{[0.05]}\end{array}$ & $(0.04)$ & $\begin{array}{c}((0.628)) \\
0.56 \\
(0.76) \\
{[0.74]}\end{array}$ & & 1.72 \\
\hline South Central & & & & & $\begin{array}{l}((0.081)) \\
(0.2) \\
{[0.2]}\end{array}$ & 0.24 & $\begin{array}{c}((0.138)) \\
0.28 \\
(0.32) \\
{[0.32]}\end{array}$ & 0.52 \\
\hline South Atlantic & & & & & $\begin{array}{c}((0.138)) \\
0.21 \\
\\
{[0.01]}\end{array}$ & $\begin{array}{c}((0.653)) \\
0.72 \\
(0.97) \\
{[0.96]}\end{array}$ & 0.04 & 0.97 \\
\hline Total Supply & 1.200 & 0.93 & 0.75 & 0.05 & 0.24 & 1.73 & 0.32 & 5.22 \\
\hline
\end{tabular}

$(())=Q P$ solution

( ) = MB solution

[ ] = LP solution

Those without parenthesis are actual flows.

on the transportation cost of the Ohio coal. Such a tax might be used to reduce the amount of acid rain due to high sulfur content in the Ohio coal. An examination of Table 4 indicates that the distribution of Ohio coal out-shipments has undergone following changes: $X_{21}$ (coal shipment from Ohio to New England) would replace $\mathrm{X}_{22}$ (Ohio to MidAtlantic) and $\mathrm{X}_{24}$ (Ohio to North Central). In addition, the number of positive coal shipments is reduced from 17 to 14 ; that is, the pollution tax would lead to a less spatially diffused shipment pattern.

\section{Concluding Remarks}

In this paper, we propose and implement the Maxwell-Boltzmann entropy model to approximate the Appalachian steam coal market. By using comparable data sets, it was found that the entropy model gives better performances than its corresponding linear programming model in terms of actual volumes and number of correct steam coal flows in the eastern United States. Furthermore, it is comparable to the spatial equilibrium model in terms of 
An Evaluation of the Maxwell-Boltzman Entropy Model

of the Appalachian Steam Coal Market

Table 4

Optimum Solution (in $10^{15}$ BTU) of the Appalachian Steam Coal Market with a One Percent per Million BTU Tax on the Ohio Coal

\begin{tabular}{|c|c|c|c|c|c|c|c|c|}
\hline To & $\begin{array}{l}\text { PA } \\
\text { MD }\end{array}$ & $\mathrm{OH}$ & $\begin{array}{l}\text { Northern } \\
\text { WV }\end{array}$ & $\begin{array}{l}\text { Southern } \\
\text { WV }\end{array}$ & VA & $\begin{array}{c}\text { East KY } \\
\text { TN }\end{array}$ & $\mathrm{AL}$ & $\begin{array}{l}\text { Total } \\
\text { Demand }\end{array}$ \\
\hline New England & & $0.03)$ & 0.03 & & & & & 0.03 \\
\hline Mid-Atlantic & $\begin{array}{c}1.03 \\
(0.54)\end{array}$ & & $\begin{array}{c}0.21 \\
(0.75)\end{array}$ & 0.02 & 0.03 & & & 1.29 \\
\hline IN-MI & $\begin{array}{c}0.07 \\
(0.09)\end{array}$ & $\begin{array}{r}0.240 \\
(0.57)\end{array}$ & 0.12 & 0.03 & & 0.2 & & 0.66 \\
\hline North Central & $\begin{array}{c}0.01 \\
(0.03)\end{array}$ & & 0.01 & & & 0.01 & & 0.03 \\
\hline Ohio Valley & $\begin{array}{c}0.09 \\
(0.54)\end{array}$ & $\begin{array}{r}0.690 \\
(0.33)\end{array}$ & 0.38 & $(0.05)$ & & $\begin{array}{r}0.56 \\
(0.8)\end{array}$ & & 1.72 \\
\hline South Central & & & & & $(0.2)$ & .24 & $\begin{array}{c}0.28 \\
(0.32)\end{array}$ & 0.52 \\
\hline South Atlantic & & & & & $\begin{array}{c}0.21 \\
(0.04)\end{array}$ & $\begin{array}{c}0.72 \\
(0.93)\end{array}$ & 0.04 & 0.97 \\
\hline Total Supply & 1.200 & 0.93 & 0.75 & 0.05 & 0.24 & 1.73 & 0.32 & 5.22 \\
\hline
\end{tabular}

Figures in parenthesis are optimal coal shipments with the one cent per million btu tax imposed on the high sulfur coals from Ohio. Those without parenthesis are actual coal flows.

actual coal flows observed in the Appalachian steam coal market using the same set of transportation costs. The simulation result from the potential pollution tax indicates that such tax may be inversed related to the number of positive coal shipments in the Appalachian market. In conclusion, the Maxwell-Boltzmann entropy formulation offers an alternative to the traditional linear and quadratic programming transportation models.

\section{Notes}

'We use Stirling's approximation $X_{i j} ! \approx X_{i j}^{X_{1 j}+0.5} \sqrt{2 \pi} e^{-x_{j j}}$ in the computer simulations (26).

${ }^{2}$ It can be shown that $\partial \log X_{i j} ! / \partial X_{i j}=\log X_{i j}$ for large $X_{i j}$.

${ }^{3}$ Another important gravity model was developed later on by Theil (1967). Since Theil's model is almost identical to that of Leontief and Strout, we shall dwell on Leontief and Strout's model. We drop the superscripts for simplicity and also limit our analysis to a single commodity.
4Some of the theorietical properties of the MaxwellBoltzmann entropy model were discussed by Yang and Loviscek (1988).

SThe data employed are from Yang (1979). In the case of Takayama-Judge model, we do not report the optimal consumption and production levels since they are endogenous and different from observed K's and D's. However, we employed the identical set of transportation costs and reported the optimum flows in Table 3.

'It implies that the linear programming model is degenerate in the sense that the actual number of positive flows is less than $\mathrm{m}+\mathrm{n}-1=13$.

\section{References}

Batten, D. F. Spatial Analysis of Interacting Economies. Boston: Kumer Nijhoff Publishing, 1983.

Brooks, R. A Spatial Equilibrium Model for the U.S. Gas Pipeline System, Ph.D. Dissertation, Massachusett Institute 
of Technology (1975).

Chao, G. S. An Efficient Method for Network Spatial Equilibrium Sensitivity Analysis, Ph.D. Dissertation, University of Pennsylvania (1983).

Charnes, A., W. W. Cooper, and A. Henderson. An Introduction to Linear Programming. New York: John Wiley and Sons, 1953.

Daffermos, S. "An Iterative Scheme for Variational Inequalities," Mathematical Programming, Vol. 26 (1983), 40-47. and A. Nagurney. "Sensitivity Analysis For the General Spatial Economic Equilibrium Problem," Operations Research, Vol. 32 (1984), 1069-1086.

Dantzig, G. B. "Application of the Simplex Method to a Transportation Problem" in T. C. Koopmans, ed., Activity Analysis of Production and Allocation (New York: John Wiley and Sons, 1951), 359-373.

Enke, S. "Equilibrium Among Spatially Separated Markets: Solution by Ecectric Analogue," Econometrica, Vol. 19 (1951), 40-47.

Evans, S. P. “A Relationship Between The Gravity Model for Trip Distribution and The Transportation Problem in Linear Programming," Transportation Research, Vol. 7 (1973), 39-61.

Gass, S. I. Linear Programming Methods and Applications, 5th edition (New York: McGraw-Hill Inc., 1985).

Georgescu-Roegen. The Entropy Law and the Economic Process (Cambridge, MA: Harvard University Press, 1971).

Hall, H., E. Heady, A. Stoecker and V. Sposito. "Spatial Equilibrium in U.S. Agriculture: A Quadratic Programming Analysis," Society of Industrial and Applied Mathematics Review (April, 1975), 323-338.

Harker, P. T. Prediction of Intercity Freight Flows: Theory and Application of a Generalized Spatial Price Equilibrium Model, Unpublished Ph.D. Dissertation, University of Pennsylvania (1983).

"A Variational Inequality Approach for the Determination of Oligopolistic Market Equilibrium," Mathematical Programming (1984), 105-111.

Hashimoto, H. "World Food Projection Models, Projections and Policy Evaluations," Unpublished Ph.D. Thesis (Department of Economics, University of Illinois, 1977).

Hitchcock, F. L. "Distribution of a Product from Several Sources to Numerous Localities," Journal of Mathematics and Physics, Vol 21 (1941), 224-230.

Irwin, C. L., and C. W. Yang. "Iteration and Sensitivity for a Spatial Equilibrium Problem with Linear Supply and Demand Functions," Operations Research, Vol. 30, No. 2 (1982), 319-335.

"Iteration and Sensitivity for a Nonlinear Spatial Equilibrium Problem," in Lecture Notes in Pure and Applied Mathematics, Vol. 85, edited by A. Fiacco. New York: Marcel Dekker Inc., 1983, 91-107.
Jevons, W. S. The Theory of Political Economy, 4th ed., (London: MacMillian, 1924).

Kantorovich, L. V. "On the Translocation of Masses," Doklady Adad Nauk SSR, Vol. 37 (1942), translated in Management Science, Vol. 5, No. 1 (1958).

Kennedy, M. "An Economic Model of the World Oil Market," The Bell Journal of Economics and Management Science, Vol. 5, No. 2 (1974), 540-577.

Khatri-Chhetri, J., J. Hite and J. Nyankori. "An Application of a Spatial Equilibrium Model for An Efficient Allocation of Water Resources," paper presented at The 27th Southern Regional Science Association Meeting, Morgantown, WV (April, 1988).

Koopmans, T. C. "Optimum Utilization of The Transportation System," Econometrica. Vol. 71 (1949), 136-146.

Labys, W. C., and C. W. Yang. "A Quadratic Programming Model of The Appalachian Steam Coal Market," Energy Economics, Vol. 2 (1980), 86-95.

Leontief, W. and A. Strout. "Multi-Regional Input-Output Analysis," in Structural Interdependence and Economic Development edited by T. Barna. London: McMillan \& Company and St. Martin's Press, Inc., 1963.

Liebman, J., Lasdon, L., Schrage, L., and Waren A. Modeling and Optimization With GINO. Palo Alto, CA: The Scientific Press, 1986.

Mineral Year Book. Washington, D.C.: United States Bureau of Mines, U.S. Government Printing Office, 1974.

Mutschler, P. H., Evans, R. J. and G. M. Larwood. Comparative Transportation Cost of Supplying Low-Sulfer Fuels to Midwestern and Eastern Coal Markets, U.S. Bureau of Mines. Washington, D.C., 1972.

Nagurney, A. “Competitive Equilibrium Problems, Variational Inequalities and Regional Sciences," Journal of Regional Science (1987), 503-517.

- "Computational Comparison of Spatial Price Equilibrium Methods," Journal of Regional Science (1987), 5576.

"An Algorithm for the Single Commodity Spatial Price Equilibrium Problem," Regional Science and Urban Economics, Vol. 16 (1986), 573-588.

Nagy, J. G., W. A. Furtar and S. N. Kulshneshta. "The Implications of a Charge in the Crowsnest Pass Freight Rate on the Canadian Prarie Wheat Economy," The Logistic and Transportation Review, Vol. 15 (1980), 284-313.

Nikjamp, P. and J. H. P. Paelinck, “A Dual Interpretation and Generalization of Entropy-Maximization Models in Regional Science," Papers of the Regional Science Association, Vol. 33 (1974), 13-31.

Pang, J. S. and D. Chan. "Itwerative Methods for Variational and Complementarity Problems," Mathematical Programming, Vol. 24 (1982), 284-313.

Samuelson, P. A. "Spatial Price Equilibrium and Linear Pro- 
gramming," American Economic Review, Vol. 42 (1952), 283-303.

Smith, T. E. "A Solution Condition for Complementarity Problems: With an Application to Spatial Price Equilibrium," Computer and Operations Research (1984), 61-69.

Smith, T. E. and T. L. Friesz. "Spatial Market Equilibrium with Flow Dependent Supply and Demand: The Single Commodity Case," Regional Science and Urban Economics, Vol. 15 (1985), 181-218.

Steam-Electric Plant Factor. (Washington, D.C., National Coal Association 1974).

Takayama, T. and G. Judge. "Equilibrium Among Spatially Separated Markets: A Reformulation," Econometrica Vol.32 (1964), 510-524.

- Spatial and Temporal Price and Allocation Models, Amsterdam: North-Holland Publishing Company, 1971.

Takayama, T. and N. Uri. "A Note on Spatial and Temporal Price and Allocation Modeling," Regional Science and Urban Economics (1983), 455-470.

Theil, H., Economics and Information Theory. Amsterdam: North Holland, 1967.

Thore, S. "The Takayama-Judge Model of Spatial Equilibrium Extended to Convex Production Sets," Journal of Regional Science, Vol. 22, 1982), 203-212.

"The Takayama-Judge Spatial Equilibrium Model with Endogenuous Income," Regional Science and Urban Economics, Vol. 12 (1982), 351-364.

Tobin, R. L. and T. L. Friesz. "Formulating and Solving the Spatial Price Equilibrium Problem with Transshipment in Terms of Arc Variables," Journal of Regional Science, Vol. 2, No. 2 (1983), 187-198.

. and T. L. Friesz. "Sensitivity Analysis for Variational Inequalities," Journal of Optimization Theory and Applications. (January, 1986), 191-204.

"Sensitivity Analysis for General Spatial Price Equilibrium," Joumal of Regional Science (1987), 77-102.

Tomlin, J. A., and S. G. Tomlin. "Traffic Distribution and Entropy," Nature, Land, Vol. 220 (1968), 97-99.
Tucker, A. W. "Analysis of Kirchoff's Law," Unpublished Naval Research Memorandum, (1950).

Walras, L. Elements of Pure Economics, edited by W. Jaffee. Homewood, IL: Richard D. Irwin, 1954.

Wilson, A. G. and M. L. Senior. "Some Relations Between Entropy Maximization Models, Mathematical Programming Models and Their Duals," Journal of Regional Science, Vol. 14, No. 2 (1974), $207-214$.

Wilson, A. G. Entropy in Urban and Regional Modeling London: Pion, 1970.

Yang, C. W. "A Critical Analysis of Spatial Commodity Modeling: The Case of Coal," Unpublished Ph.D. Dissertation. West Virginia University (1979).

"Quadratic Programming and Spatial Equilibrium: The Case of Coal," National Technical Information Report No. PB\#301365, Washington, D.C., National Science Foundation (1980).

"The Le Chatelier Principle and the Convex Programming Analysis of the Spatial Equilibrium Models," in Modeling and Simulation, Vol. 13. Instrument Society of America, 1982, 52-60.

and W.C. Labys. "A Sensitive Analysis of the Stability Property of the QP Commodity Model," Journal of Empirical Economics, Vol. 7 (1982), 93-107.

"Stability of Appalachian Coal Shipments Under Policy Variations," The Energy Journal, Vol. 2, No. 3 (1981), pp. 111-128.

"ASensitivity Analysis of the Linear Complementarity Programming Model: Appalachian Steam Coal and Natural Gas Markets," Energy Economics, Vol. 7, No. 3 (July 1985), pp. 145-152.

"A Maxwell-Boltzmann Entropy Model of the Appalachian Steam Coal Market, " paper presneted at 1989 Society of Industrial and Applied Mathematics Conference, San Diego.

Yang, C. W. and A. Loviscek. "A Critical Analysis of the Spatial Equilibrium and Maxwell-Boltzmann Entropy Maximization Problem," paper presented in 1988 Southern Regional Science Association, Morgantown, WV (April 14-16, 1988). 